\title{
E-LEARNING A LINGUISTIC RURAL PERSPECTIVE
}

\author{
Fakkiravva Muttagi ${ }^{1}$, S L Deshpande ${ }^{2}$ \\ ${ }^{I}$ M.Tech Student, Department of Computer Networks and Engineering, VTU, PG Center, Karnataka, India \\ ${ }^{2}$ Head of Department, Department of Computer Networks and Engineering, VTU, PG Center, Karnataka, India
}

\begin{abstract}
India is a multilingual developing nation with increasing literacy rate of $74 \%$ (as per census). Lack of available literacy is not supported with content or skilled trainers. So technology is available but the content and effective synchronous and asynchronous models e-learning have not been attempted effectively. Effective assessment of e-learning is not tested. An attempt has been made in this article to gather the requirement from Karnataka rural areas, NGO (RAPID) and developed the e-learning application for rural area to enhance their skills and increase literacy in regional language to provide knowledge in a local language.
\end{abstract}

Keywords: E-learning, Mobile Development, Rural Development, Literacy

\section{INTRODUCTION}

Literacy is always considered to be an essential input for socio-economic growth of a nation. Economic success of a country depends on the economic resources it has and human source is a significant part of economic resource. Human resource includes the population, its growth percentage, skills, standard of life and the working ability of the human and all the factors can be enhanced by growing the literacy rate. Thus literacy rate acts as an important role in economic growth of a country. Human resource is the biggest asset of India, efficient utilization of the human resource becomes very necessary for the country's financial development and thus literacy plays an important role in shaping India's growth.

Just being educating does not make people capable enough to get a job. Improving additional skills is an essential in a country like India which has a lot of unemployment. Unskilled workers are seasonally employed, mainly in agricultural fields, and paid minimal salaries. Improving skills in these workers will guarantee them more good jobs and gets higher salary. [1]

Skill increasing method, which connects to work It can facilitate countries maintain productivity growth and convert that growth into more and better jobs. In the $21^{\text {st }}$ century, one of the most main technologies is the digitization. The system, which allows persons to communicate globally one more part of digitization, is the sequence of smartphones that gives the single contact to access the online services all over the world. With Digital India, by connecting all services with the e-learning this facility will mean to minimize the usage of physical documents and allow sharing of e-learning across India. Mobile applications and web portals gives freedom to access the data while travelling. [2]
The main characteristic of E-Learning is the flexibility in access documents and resources. It can access the documents and resources at any time and any area. Student is not restricted with the limitation of attending the classes on set time and fixed area. Another characteristic is access of multimedia base assets; it means that types of media like text, audio, video, graphics, animation, picture, which makes feasible accessing of information, which makes students more interesting and efficient. [3]

Implementing e-learning in Indian rural place is a difficult because; rural people are usually financially backward and cannot afford money for buy laptop/desktop. Internet access is difficult as in rural places, the network speed is less. Typically for downloading/watching videos takes much time to load. They should know at least minimum basic knowledge on how to access mobile application and web portal. Rural area people usually communicate in local languages, so they cannot completely understand the flow of the application in English.

E-learning in India failed to educate Indian rural because of:

\section{Insufficient E-learning infrastructure}

The main tools like computers, network and internet connectivity, and computer laboratory as insufficient in rural places to maintain the large numbers of students who desire to access e-learning web portal.

\section{Financial limitation}

Execution of e-learning is usually costly for rural places at the early startup stage. Insufficient finance of e-learning is therefore a main obstacle to its successful execution in Indian rural place. 


\section{Lack of affordable and sufficient Internet bandwidth}

Lack of affordable and sufficient Internet bandwidth; it is one of the challenging for execution of e-learning.

\section{Lack of technical skills on e-learning development by}

\section{the teaching staff.}

Technical skill on e-learning application by the instructor is a challenge for execution of e-learning in rural areas. This is attributed to insufficient or lack of training in e-learning skills. Although some of the instructor have basic computer literacy skill, this skill might not be sufficient them to utilize e-learning in coaching as well as building e-content, thus they need training.

\section{Lack of attention and dedication among the instructors} to utilize e-learning

It is one challenge for execution of e-learning. This is recognized as a lack of inspiration among the instructors who transfer their courses to e-content as additional job with no extra pay.

\section{Quantity of time necessary to build e-learning content}

Developing e-content takes a much time, hence for the execution of e-learning in rural areas. It came out clearly that most instructors are busy with regular teaching and other tasks; consequently do not have sufficient time to transfer their courses from hard copy to e-content soft copy.

\section{LITERATURE REVIEW}

In the word e-learning "e" confers with electronic wherever it might incorporate all academic activities disbursed on-line or offline [4]. E-learning is that the laptop/desktop/mobile application and network-enable transfer of skill and instructions. E-learning, a general term for education, coaching and knowledge or/and data emphasizes collecting skills and knowledge. It is a technique that evolved from distance education that permits data sharing and learning while not the constraints of your time or place [5].

Content is broadcasted via the network, intranet, and digital audio or digital video. It is self-pace or instructor and include media in the style of text, figure, cartoon/animation, streaming videos and audios.

The current day e-learning is separated into two categories: synchronous and asynchronous.

\section{Synchronous e-learning:}

Connect online learning via chatting and video conferences. This type of e-learning tool is real-time. It is similar to virtual classrooms which allow student to rise, and instructors to reply questions immediately, via immediate message, it is called synchronous. As an alternative of taking training alone, students join them with synchronous e-learning application can easily work together with associate students and their instructors during the classes. Example for Synchronous e-learning is chatting and Internet Messaging, videos and audios conferencing, live webcast, applications sharing and practical classroom.

\section{Asynchronous e-learning:}

Events are time-independent .e-learning application can study even the student is offline. It contains homework delivered through internet, email and messaging are then send on online blogs. In such case, student preferably completes the study at their individual speed [6].

Most of the developers choose the learning Methods from the Asynchronous model. Below are the some areas where user can select e-learning method base on the prerequisites.

\section{- Self-study:}

It uses Wikipedia, blog or studying materials like power point presentation, pdf for suggesting the early information to students. This can permits topic expert to the collection of students to the class to decide their questions and doubts.

\section{- Video and audio:}

This method is to build demonstration videos to educate students. It helps to generate one mode of student asset it helps the student to know on the basic by watching videos.

\section{- Computer-based training and Web-based training:}

In this, E-learning documents are available to students in the type of a CD or DVD, it can be execute on the student's computer machine. E- Learning can also be accessible via Web-based training (WBT), it uses internet. The tutorial is self-paced, and the students have no contact with teachers.

\section{- Blended E-learning:}

This is combination of Synchronous and the Asynchronous e-learning models. A few courses, like soft-skill, have faceto-face factors in order to be really impactful.

\section{- Mobile Learning:}

The simple accessibility and cost effectively for mobile phone tools has shaped the gap for mobile learning method. Converting e-learning web portal to mobile friendly module is not enough. The capability of the mobile phone device, together with memory size, internet, and the dimension of screen has to be taken into consideration.

Selecting the right E-learning model completely depends on the appropriate requirement study of the society and upon the environment of the student and their cooperation methods [7]. 


\section{ARCHITECTURE OF MOBILE}

\section{APPLICATION FOR E-LEARNING}

\section{Mobile Web Apps:}

It is a web app designed for mobile phones, and is access via the mobile phone tool's internet. Mobile web application is built with 3 technology: HTML (a static page), CSS (style and presentation page), and JavaScript (interactions and for animation).They are planned for platform and gadget free, able to execute on every network-enable mobile phone.

\section{Mobile Native Application:}

Native mobile application is build especially for particular gadget and OS. It is access through internet; Native application can download from an internet and installed on mobile device. Native applications are developed in Java, C, or other programming languages.

\section{Hybrid Applications:}

A native Applications and Web Applications are used to build customized native applications for various mobile phones. Combination of two technologies made a hybrid application. By hybrid application, the entire client interface show in browsing windows, with native application covers on it to give access to gadget, functionality not existing via the browser. This capacity to join standard web applications and native application can considerably decrease development duration and charge, decreasing the custom coding job. However for developer there is vast variation, since other than reworking the full application for individual mobile tool, developer writes some codes in HTML, JS and CSS and use again across many device [8].

\section{COURSE DESIGN}

\subsection{E-Learning in Kannada Language}

Indian teaching structures have been agreed that regional languages are thought from schooling. In rural places users are not exposing much for English language. In Karnataka rural people uses Kannada language for reading, research, learning and education. It will be useful for rural places if the course is in Kannada language rather than an English language.

\subsection{Course Content}

The contents are developed by the expert. Knowledgebase is constantly rising from history. Course consists of

- Subject lecture developed by expert.

- Learning materials

- Lecture and multimedia base interactive source

- Video content

- Records of users gather during e-conversation, file forum etc [9].

\subsection{Application Design}

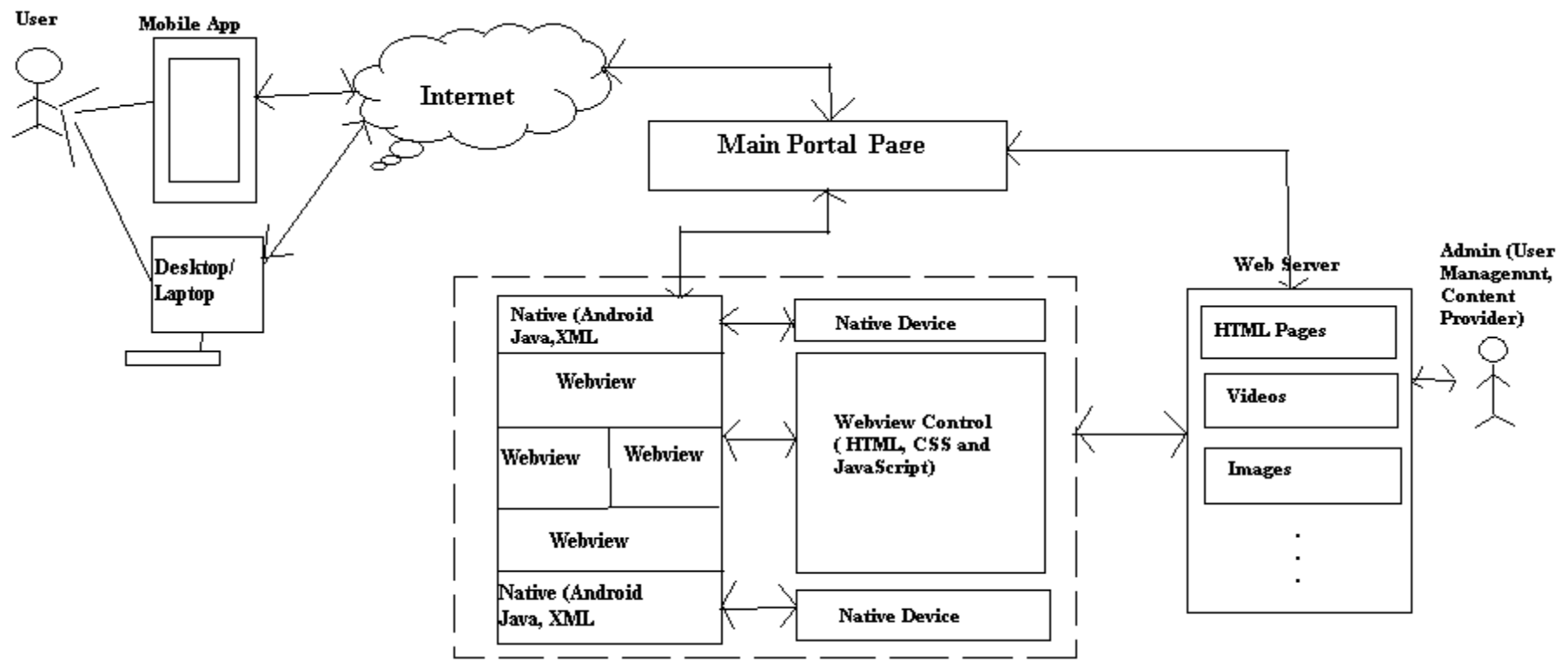

Fig-1: Architecture of E-Learning through Hybrid app

Hybrid application is embedded with HTML code. Chosen part of the Application are written using web technologies. The web parts of the result either be downloaded through the web or packaged inside the android application. Hybrid applications have two separate components:
The native part of the application can call the API supplied by the OS it means, it can free access to all the gadget suggests.

Second part is the WebView part of the application is written in HTML CSS and JavaScript are executed by the rendering machine that is WebView. By default this web 
system can access the services that rendering machine represents. But the native part of the application has control through the rendering machine and as it creates a bridge that permits the web portal to the application to access the services.

Kannada e-learning application is developed with Kannada as an interacting language. The requirement are gathered from Karnataka NGO (RAPID - empowering women in distress) and the developed architecture was tested on a sample of 20 candidates and has produced better skill enhancement. The course was specifically designed to understand the fundamental of ICT for skill up gradation of such candidates, using Kannada as a language. This application is successfully launched and done Beta testing at ganaka.eastwestideation.com.

\section{TESTING CRITERIA}

In these days multimedia devices come in different size and shapes like laptop, desktop computer, and smart phones in use. Users nowadays require design and build application that can be access on immediately in any tool a user may have.

Testing E-learning application that should be planned to execute on various tools produces some distinctive challenges.

\section{Is text can be read easily?}

- Text can show larger and smaller based on tool resolution.

- Italicize text can be difficult to read, particularly on small tools. Such format is best to avoid for easiness of reading on small tools.

- As of ease of accessible perception, a general setting is font size - as text box auto-resize to hold even large font sizes.

\section{Is the content properly aligned?}

- It is advice to the content be check on the target configuration and on user tools. Each browser has its HTML rendering machine, which shows the content with a lightly dissimilar pages and text format, tending to difference in alignment.

- Designing perceptive, a little graphics for interactive element define good for identification.

\section{Is the navigation works correctly?}

- For small tools like mobile phones, it is suggested that navigation be sensibly grouped and covered.

- A GUI design where few controls are automatically enabled on tool kind and size.

Is illustration suggestions gives for new or specific signs?

- If E-learning contains interactivity that needs particular signs, it should provide a user to know the clear idea of specific sign to be mention in first.

\section{Are the interactivities appropriate for every tool?}

- Interactivity in multiple tools E-learning should work easily on all targeted tools and it should be customized for different tools type and size.

- An extra or different interaction choice can be supplied based on tool.

Are the identical meaning and connection among pieces of content maintained in different layout?

In multiple tools E-learning, content design varies depends on tool size, it's significant to verify that the identical meaning has been maintained [9].

\section{CONCLUSIONS}

An attempt is made by the authors to integrate the internet world to the rural population of the country for educating rural India. The developed content has textual as well as multimedia content to enhance the learning experience. Use of a local language impact to the better experience of learner. The authors also claim that use of technology on the figure tips improves the accessibility of the knowledge. This work has been carried out at an NGO (RAPID empowering women in distress) which supports socially challenged women.

\section{ACKNOWLEDGEMENT}

I hereby say my sincere thanks to Dr S L Deshpande for their constant support and encouragement. I would also like to thank NGO: RAPID- empowering women in distress for their constant encourage and co-operation for competing this paper and application.

\section{REFERENCES}

[1]. Vaman S Desai "Importance of Literacy in India's Economic Growth" IJER, MAR - APR 2012.

[2]. Sudhir Kumar Sharma,Vandana Lama, Nidhi Goyal, "Digital India: A Vision Towards Digitally Empowered Knowledge Economy", INDIAN JOURNAL OF APPLIED RESEARCH, Volume : 5 | Issue : 10 | October 2015.

[3]. Abbas Pourhosein Gilakjani , "The Significant Role of Multimedia in Motivating EFL Learners' Interest in English Language Learning", I.J.Modern Education and Computer Science, 2012.

[4]. Durgaprasad and K. Hussain, "E-learning Technology for Rural Development", Asian Journal of Management, Engineering \& Computer Sciences (AJMECS), Vol. 1(1), January 2016.

[5]. Ijaz A. Qureshi, Khola Ilyas, Robina Yasmin , Michael Whitty" Challenges of implementing elearning in a Pakistani university ", Knowledge Management \& E-Learning: An International Journal, Vol.4, No.3.2012.

[6]. https://www.mindflash.com/elearning/asynchronoussynchronous 
[7]. http://elearningindustry.com/3-easy-methods-createelearning-videos

[8]. "Mobile Web Apps vs. Mobile Native Apps: How to Make the Right Choice", Lionbridge

[9]. Shivpal Singh Kushwah, J K Vijayakumar" Content creation and E-learning in Indian languages: a model"

[10]. https://www.upsidelearning.com/blog/index.php/2014/ 02/20/testing-of-multi-device-elearning-projects/ 